\title{
REALISMO MÁGICO. HISTORIA E INTRAHISTORIA EN EL CINE IBEROAMERICANO
}

\author{
Juan Aquilino Cascón Becerra \\ UNIVERSIDAD DE CÁDIZ
}

\section{RESUMEN}

Este artículo muestra la especial relación entre el cine iberoamericano, la Historia e Intrahistoria de Iberoamérica y el Realismo Mágico. En el mismo se comenta la dificultad para definir un término que abarca el arte, la literatura y el cine. Igualmente se enumeran una serie de autores tanto iberoamericanos como de otros países, y de películas del Realismo Mágico.

Palabras clave: Historia, cine, Iberoamérica, literatura, recursos didácticos.

\section{ABSTRACT}

This article shows the special relationship between latinoamerican cinema, the History of Latin America and the Magic realism. It includes a list of Magic realism writers from Latin America and anothers countries, the polemic about the significate of Magic realism and a list of latin americans movies who includes Magic realism and History of Latin America.

Key words: Cinema, research, didactics resources, Latin America, History.

Realismo Mágico es un término muy difundido actualmente, si bien dista hoy de tener el mismo significado que tuvo cuando fue creado en las primeras décadas del siglo Xx. Todo aquel usuario de Internet que viera desde principios del mes de octubre de 2006 el portal Yahoo.España se encontraría en el centro de la pantalla con el siguiente anuncio: Realismo mágico. La nueva edición del videojuego FIFA 07 ofrece una experiencia de juego casi real. Parece evidente que esta muestra de la popularización del término ${ }^{1}$ leva consigo una banalización del mismo, y su devaluación por cierto

El propio Mussolini llegó a adjetivar con el término Realismo Mágico a los productos estéticos del fascismo en los años treinta del pasado siglo. 
número de autores. Aunque usado, no parece a primera vista preciso: ¿Realismo Mágico o Fantástico?, ¿equivalente al tan cacareado Boom $^{2}$ de la literatura hispanoamericana, al conjunto de la literatura de Iberoamérica, a todo lo proveniente de esta parte del mundo? Para comprender la importancia del Realismo Mágico dentro del cine iberoamericano como instrumento de estudio, difusión e investigación de la Historia y de la Intrahistoria de Iberoamérica, es necesario un primer acercamiento al significado del propio término y a su relación con la literatura de América Latina como paso previo a su relación con el cine iberoamericano.

\section{¿QUÉ ES REALISMO MÁGICO?}

Lo confuso del término no impide saber que tuvo un origen reconocido por la casi la totalidad de los autores especializados, y un origen además externo a América Latina, y casi a la literatura. Así, la polémica sobre qué es concretamente el Realismo Mágico se da décadas después de que nazca el término en Alemania, con la publicación del libro del crítico Franz Roh titulado Nach-Expressionismus (Magischer Realismus) en 1925, dos años más tarde traducido al español como Realismo mágico, Post Impresionismo, por la Revista de Occidente en el Madrid de $1927^{3}$. En esta obra se caracteriza al arte post-expresionista como afecto a un nuevo objetivismo, revelador desde lo concreto de los misterios que la realidad oculta. Roh utiliza el adjetivo "mágico" como índice de un misterio que se esconde y late dentro del mundo representado. Posteriormente, en el ámbito de las artes plásticas, fue remplazado por el término "nueva objetividad" y de ahí pasa a partir de los años 50 y 60 de siglo XX a relacionarse con la literatura hispanoamericana como veremos a continuación.

Poco después utiliza el mismo término el italiano Massimo Bontempelli, quien a su vez influye en quien incorpora por primera vez esta denominación a la crítica de la novela hispanoamericana, el escritor venezolano Arturo Uslar Pietri. Este autor caraqueño escribe en $1948^{4}$ que el planteamiento de lo humano como misterio podría denominarse, a falta de otras palabras, un Realismo mágico. A partir de entonces el término cobra fama y difusión; se califica o clasifica como Realismo Mágico a un gran número de obras y autores sin que al mismo tiempo se defina teóricamente con cierta coherencia y precisión dicha definición. Algunos llegan a confundir el Realismo Mágico con la simple fantasía (literatura fantástica), si bien esto es criticado en la década de los sesenta por quienes retoman la idea originaria de Roh.

Esta confusión llevó a un desprestigio del término. En 1973 Emir Rodríguez Monegal abogaba en un congreso de hispanoamericanistas por su abandono, considerando al Realismo Mágico como un lastre para la comprensión de la literatura de Iberoamérica.

Otros autores sin embargo, reclamaron, de manera más acertada, una formulación teórica rigurosa del Realismo Mágico como categoría histórico-crítica válida para el estudio de la novelística hispanoamericana, como Lucila-Inés Mena ${ }^{5}$. En 1985 aparece una obra de Amaryll

2 Bajo esta onomatopéyica expresión anglosajona se resume el periodo de auge de la literatura hispanoamericana, que según ciertos autores se inicia en 1940, y según otros tiene su apogeo en los años 60 y 70 . Al menos en España la expresión tiene una clara relación con la propaganda que las editoriales del momento hacían de algunos escritores iberoamericanos. La expresión cobra cierta fama gracias también a una obra de uno de sus protagonistas, el chileno José Donoso, que escribe en 1972 las memorias tituladas Historia personal del boom.

3 El destacado especialista en literatura hispanoamericana MENTON, Seymour ha prolongado el rastreo iniciado por Franz Roh desde el post-expresionismo hasta el arte de los 80 en su libro Magic Realism Rediscovered, 1918-1981, Filadelfia, Londres y Toronto, The Art Alliance Press-Associated University Presses, 1983.

PIETRO, Uslar: Letras y hombres de Venezuela, México, FCE, 1948.

5 MENA, Lucila Inés: Hacia una formulación teórica del realismo mágico, Bulletin Hispanique, 1975. 
Beatrice Chanady ${ }^{6}$ que da respuesta a las demandas de Mena, al separar el término Realismo Mágico de la literatura fantástica. Si bien lo fantástico y el Realismo Mágico nos hablan de dos planos de la realidad, lo natural y lo sobrenatural, lo racional y lo irracional, en el Realismo Mágico cambia la forma en que ambos planos se relacionan entre sí, de modo que dentro del Realismo Mágico hay una especial armonía entre ambos.

Lo sobrenatural, lo irracional, no es presentado como problemático ni para los protagonistas de la obra ni para los lectores de la misma. Dentro del Quijote encontramos una líneas que aclaran en cierto grado esto último: Hanse de casar las fábulas maravillosas con el entendimiento de los que las leyeren, escribiéndose de suerte que, facilitando los imposibles, allanando las grandezas, suspendiendo los ánimos, admiren, suspendan, alborocen y entretengan, de modo que anden a un mismo paso la admiración y la alegría juntas (I, 47).

Podemos reiterarnos en la idea de que en el Realismo Mágico lo natural y lo sobrenatural conviven de modo coherente, de que tanto lo racional como lo irracional (se podría decir que los dos hemisferios del cerebro humano, con los atributos pertenecientes a cada uno de ellos) configuran el conjunto de una realidad que se nos manifiesta mestiza por lo citado, una realidad que es síntesis de dos mundos separados pero no enfrentados.

En 1980 aparece en Brasil una obra de Irlemar Chiampi ${ }^{7}$ que arroja luz sobre el término Realismo Mágico. No obstante serán las aportaciones de los propios autores latinoamericanos los que aclaren y aporten nuevos puntos de vista al término como ya veremos en el apartado sobre la relación entre Realismo Mágico y Literatura.

En conjunto podemos enumerar una serie de características del Realismo Mágico aplicables tanto a la literatura como en su momento quedará expuesto, al cine:

Lo primero es el contenido de elementos mágicos/fantásticos, percibidos por los personajes como parte de la "normalidad".

- Elementos mágicos tal vez intuitivos, pero nunca explicados. Presencia de lo sensorial como parte de la percepción de la realidad.

- El tiempo es percibido como cíclico, no como lineal, según tradiciones disociadas de la racionalidad moderna occidental.

- Se distorsiona el tiempo, para que el presente se repita o se parezca al pasado.

- Transformación de lo común y cotidiano en unas vivencias que incluyen experiencias "sobrenaturales" o "fantásticas".

- Preocupación estilística, partícipe de una visión "estética" de la vida que no excluye la experiencia de lo real/ irreal.

Otra característica del Realismo Mágico es la referente a la temática. Así, dentro de lo mágico podríamos encontrar también elementos de auto-reconocimiento de los escritores iberoamericanos, la búsqueda y justificación de sí mismos e identidad latinoamericana fuera del contexto europeo. La temática se extrae de tres aspectos fundamentales americanos:

- Diversidad de épocas históricas.

- Esencia cultural del mestizaje.

- Lo prehispánico o indígena en sus valores mitológicos.

6 CHANADY,A. B.: Magical Realism and the Fantastic: Resolved versus Unresolved antinomy. Nueva York-Londres, Garland, 1985.

7 CHIAMPI, I.: O Realismo maravilhoso. Forma e Ideología no Romance Hispano-Americano. Sao Paulo, Perspectiva, 1980. 
El tratamiento que se da al factor Espacio es también original. Así, es

- Mínimo y vital

- Dinamiza y activa el contenido de las acciones

- Atmósfera interiorizada- hoy

- También posibilita observar las figuras gramaticales de esa época.

Los personajes presentes en las obras de esta corriente de vanguardia, suelen tener viajes no de tipo físico como los que sufren los personajes de las obras criollistas para dar un ejemplo, sino que estos cambian de espacios y tiempos desde sus pensamientos y estados oníricos.

\section{REALISMO MÁGICO Y LITERATURA.}

Popularmente se tiende a confundir al Realismo Mágico $^{8}$ con todo tipo de literatura proveniente de América Latina. Algunos colocan ese membrete a las obras y autores protagonistas del Boom de los años sesenta y setenta y otros creen que el término existe a partir de las obras del colombiano Gabriel García Márquez. Para el gran público, Realismo Mágico casi equivale a sus Cien años de soledad y poco o nada más. Pero hay precedentes: años antes de que García Márquez escribiera su famosa obra en 1967, el mexicano Juan Rulfo escribió en 1955 Pedro Páramo. Y años antes, en 1949, el cubano Alejo Carpentier escribe El Reino de este mundo. Y antes aún, en 1940, el ecuatoriano José de la Cuadra ${ }^{9}$ escribe un libro de relatos, Horno, precisamente el mismo año en que algunos autores dan comienzo a la moderna narrativa hispanoamericana.

Hay que tener en cuenta también que dentro del Realismo Mágico encontramos obras y autores que no son iberoamericanos. Algunos no han tenido relación o han sido influidos por los escritores hispanoamericanos; otros demuestran en sus obras la clara influencia del Realismo Mágico latinoamericano. Dentro del mundo anglosajón ${ }^{10}$, se considera a escritores tan diversos en

8 Dentro de las obras en español que tratan sobre el Realismo Mágico y la literatura hispanoamericana podemos citar la de SÁNCHEZ FERRER, J. L.: El realismo mágico en la novela hispanoamericana en el siglo XX. Madrid, Anaya, Madrid,1990; MENTON, Seymour: Historia verdadera del realismo mágico. México, Fondo de Cultura Económica, 1998; la obra de VILLANUEVA, Dario y VIÑA LISTE, José María: Trayectoria de la novela hispanoamericana actual. Del "realismo mágico" a los años ochenta, Madrid, Espasa Calpe, 1991; y como evidencia del avance de la lengua española en los Estados Unidos, la obra de MARTíN JUNQUERA, I. : La literatura chicana y nativo americana ante el realismo mágico, editada por la Universidad de León en 2005.

9 José de la Cuadra nace en Guayaquil en 1903. Destacado por su realismo didáctico en defensa de los indígenas y de las clases sociales más depauperadas. Fue doctor en Jurisprudencia y profesor universitario. De tendencia socialista, creó una universidad popular en su ciudad natal y ocupó altos cargos en la Administración de su país. También perteneció al grupo de Guayaquil, cuyo lema era "la realidad y nada más que la realidad". Su evolución literaria pasó de la novela rosa y galante a la social, tremendista y testimonial, aunque en sus argumentos siempre hay un lugar para los mitos y leyendas, y en su última época mostró un gran interés por los análisis científicos en el campo de la etnografía. Su primera obra la publicó en 1931, Repisas (narraciones breves), y era una colección de cuentos; siguió Horno (cuentos, 1932), obra muy lírica sobre la situación de los montuvios, los campesinos de la costa. En su novela Los Sangurimas, novela montuvia ecuatoriana (1934) vuelve a tocar la misma situación en una historia de venganzas en las llanuras salvajes de Ecuador y está considerada su mejor obra. El montuvio ecuatoriano (ensayo de presentación), publicado en 1938, desarrolla otra vez el tema, desde un punto de vista sociológico. Además publicó otras colecciones de cuentos Guasintón: relatos y crónicas (1938) y Los monos enloquecidos (1951)-, y ensayos, entre ellos Doce siluetas (1934).

10 Entre las obras recientes en inglés que abordan el análisis y estudio del Realismo Mágico destacaría las de BOWERS, Maggie: Magical Realism, Routledge, 2004, la de SCHROEDER, Shannin: Rediscovering Magical Realism in the Americas, Praeger, 2004, y la de los autores ZAMORA; PARKINSON, Lois y FARIS, Wendy B. eds. Magical Realism: Theory, History, Community, Duke University Press, 2003. En francés destaca la obra de RUAUD, André-François: Réalisme magique, un autre regard sur le monde, in Panorama illustré de la fantasy \& du merveilleux, Lyon, Ed. Moutons électriques, 2004. 
estilo y origen como Sherman Alexie, Louis de Bernières (influido por García Márquez), Mijail Bulgakov, Italo Calvino, Angela Carter, Michael Gow, Günter Grass, Ernst Jünger, Franz Kafka, Daniel Kehlmann, Milan Kundera, Onat Kutlar, Yann Martel, Jonathan Lethem, Toni Morrison, Haruki Murakami, Ben Okri, Arundhati Roy, Ngugi wa Thiong'o o el iraní Salman Rushdie como autores que han cultivado el estilo del Realismo Mágico. Por lo tanto no estamos ante un fenómeno exclusivamente iberoamericano, pero sí es cierto que en América tiene una relevancia y una importancia por su relación con la Historia y la Intrahistoria mayor que en otras partes del mundo.

Dentro de los autores iberoamericanos, y según los parámetros anglosajones, encontramos a escritores como el hispano Rudolfo Anaya, Isabel Allende, el brasileño Mário de Andrade (autor de la novela Macunaíma 1928, considerada por algunos como un precedente claro del posterior Realismo Mágico del Boom y llevada al cine en 1969 por el realizador brasileño Joaquim Pedro de Andrade), Miguel Ángel Asturias, Adolfo Bioy Casares, Jorge Luis Borges, Alejo Carpentier, Julio Cortázar, Laura Esquivel, Carlos Fuentes, Dias Gomes, el californiano Gilberto Hernández, Xaime Hernández, Mario Vargas Llosa, Gabriel García Márquez, Arturo Uslar-Pietri o Juan Rulfo. Verdaderamente no toda la producción de estos autores puede considerarse realista-mágica, ni quizá todos los autores citados (algunos incluyen al subcomandante Marcos por sus escritos), pero sí han creado en algún momento obras que encajan con las características estilísticas.

En España también hay autores que cultivaron en algún momento de su obra el Realismo Mágico. Es el caso del gallego Wenceslao Fernández Flórez o el canario Rafael Arozarena, autores que fueron adaptados al cine como veremos más adelante. Dentro de Andalucía, en la provincia de Cádiz, se ha considerado a Fernando Quiñones como un escritor encuadrado dentro de un cierto Realismo Mágico, sobre todo por sus obras La guerra, el mar y otros excesos, de 1966, formada por varios relatos, y Nos han dejado solos, de 1980, otro libro de relatos donde el autor se basa en la idea del eterno retorno.

El Realismo Mágico iberoamericano hunde sus raíces en su pasado histórico mestizo, que combina las culturas prehispánicas y las interpretaciones de los europeos en las sucesivas colonizaciones del continente. Debemos aquí recordar las crónicas de los exploradores y conquistadores españoles del siglo XVI, ricas en el relato y descripción de todo tipo de maravillas. Es el caso de las crónicas que nos describen a animales fabulosos, a personajes de leyenda, a ciudades fantásticas, como las de Cabeza de Vaca después de recorrer a pie miles de kilómetros por el sur de Norteamérica. A partir de esta tradición de la interpretación de la realidad del Nuevo Mundo a través de los ojos de los españoles y de otros europeos se crea una visión sobrenatural de la realidad iberoamericana.

Durante las décadas de los años 20 y 30 del siglo Xx muchos artistas y escritores iberoamericanos viajaron a Europa para incorporarse a las vanguardias artísticas, principalmente al rompedor surrealismo, buscando aquellos aspectos sobrenaturales necesarios para desarrollar una realidad basada en el subconsciente y en el mundo de los sueños, en lo onírico. El surrealismo pretendía entre otras cosas eliminar la frontera entre realidad y sueño, entre objetividad y subjetividad, entre razón y locura, dicotomía ésta alejada de la burguesa razón o fuerza de los decimonónicos libertadores.

A su regreso a Iberoamérica, se dieron cuenta de que no era necesario buscar esas realidades extrañas en el Viejo Mundo, que podían encontrarlo en sus propios países y culturas. Uno de los primeros escritores en descubrir todo esto fue Alejo Carpentier junto con la también cubana Lidia Cabrera. Ambos se encontraban en la siempre idealizada París en la misma época, pero los planteamientos teóricos de Carpentier, que en parte escaparon a su propia aplicación, fueron aprovechados por Cabrera. La rígida formación intelectual de Carpentier le impidió penetrar en lo que él mismo definía como novedoso, mientras que el empirismo de la 
autora cubana le permitió capturar en parte el Realismo Mágico de lo afro-caribeño. A partir de los años 30 las obras de los psicoanalistas habían calado entre la intelectualidad europea; se rechazaba al mundo moderno occidental buscando refugio en un pasado mítico o mitificado y también otras culturas de un modo eurocentrista y racista, ya que se exploraba el mundo de gentes inferiores. Esto nos recuerda en parte al Museo Quai Branly, recientemente inaugurado en París y dedicado al arte tradicional o de civilizaciones antiguas de Asia, África e Iberoamérica, separado del occidental Louvre, lo que no deja de tener cierta connotación eurocentrista diferente del prestigioso Museo Británico de Londres, donde en una misma colección aparecen juntos objetos europeos de diversos lugares y épocas con aquellas obras que el Imperio británico obtuvo de manera más o menos lícita a lo largo de siglos. Se podría pensar que los británicos, con sus rapiñas artísticas, elaboraron el prefacio de la actual globalización económica mundial.

Los escritos del francés André Breton Los campos magnéticos y Manifiesto del surrealismo tuvieron un enorme impacto entre los intelectuales de ambas orillas del Atlántico, pero los americanos se dieron cuenta de que lo que habían dejado atrás tenía sentido, ya que las comunidades indígenas y negras vivían en una realidad afincada en lo mágico si recurrir a los sueños o a los psiquiátricos. El guatemalteco Miguel Ángel Asturias llega a declarar a Claude Couffon en 1962: mon réalisme est magique parce qu'il relève un peu de revé, tel que le concevaient les surréalistes. Al querer alejarse del surrealismo, Carpentier identifica en su intento por analizar culturalmente la América Latina desde la literatura como lo real maravilloso. Curiosamente la atracción por lo maravilloso no nacía del contacto con lo autóctono, sino con el surrealismo parisino. Considera el autor cubano que las técnicas surrealistas son equivocadas por el absoluto sentido artificial de lo maravilloso. Desde entonces se aleja del surrealismo y penetra en la realidad americana plenamente.

Carpentier sostiene que existe una vigencia en pleno siglo XX de una serie de mitologías y creencias con las que contacta después de volver de Europa a Cuba en 1939 y sobre todo, de su visita en 1943 a Haití. Su teoría sobre lo real maravilloso queda expuesta en el prólogo de su famosa obra El reino de este mundo. Contrapuesta a los rasgos conceptuales surrealistas, su teoría expresaba los profundos cambios que maduraban en el reflejo de esa realidad en la novela, y que empezaban a manifestarse en otros novelistas iberoamericanos.

Algunos autores creen que lo real maravilloso de Carpentier va más allá de un pintoresco costumbrismo, pero que deja casi ocultas las luchas por la liberación y los conflictos sociales que las originan. El concepto de lo maravilloso implica una sorpresa ante fenómenos no habituales o inesperados. Puede ocurrir como resultado deliberado de la manipulación de la realidad, por la percepción del artista y por intenciones sobrenaturales que provocan la presencia de algo diferente de lo normal.

Alejo Carpentier juega con esta categoría en diferentes direcciones, pero sintetiza $s u$ Realismo Mágico en tres puntos: primero, como una literatura maravillosa de origen europeo con referencias a fenómenos sobrenaturales; segundo, la realidad maravillosa es más maravillosa que esa literatura y, por lo tanto, cabe hablar de lo maravilloso americano; tercero, que lo "real maravilloso" de Iberoamérica podrá trasladarse a la literatura solamente a condición de que los escritores sostengan que esa América es maravillosamente real. Para los historiadores la importancia del escritor cubano radica en que enseñó que la novela no sólo comunica un placer estético, sino que se convierte en instrumento destacado de indagación en la realidad, un método de conocimiento sobre hombres y épocas históricas.

Sobre esa realidad tan característica como es la iberoamericana debemos señalar que el impacto ejercido sobre los primeros europeos llegados al Nuevo Mundo fue tal que no disponían de palabras precisas, por lo que se tuvo que elaborar casi un nuevo lenguaje. Se puede hablar 
aquí de unidades culturales o ideologemas ${ }^{11}$, entendidas como sistemas semánticos dentro de un código de determinadas convenciones. Para Irlemar Chiampi existen dos unidades culturales operantes en la novelística hispanoamericana del siglo xx: el ideologema de crónica o de maravilla, que arranca de las primeras visiones de las entonces llamadas Indias dadas por escrito; y, de modo complementario, el del mestizaje, derivado de la fusión de lo heterogéneo, de síntesis de aparentes contradicciones, de amalgama de razas, pueblos y culturas que es Iberoamérica.

\section{CINE Y REALISMO MÁGICO. RELACIÓN CON LA HISTORIA E INTRAHISTORIA DE IBEROAMÉRICA.}

La relación entre Cine e Historia cobra una singular importancia con el Realismo Mágico, pues gracias a él se incorpora plenamente la Intrahistoria, que abarca las historias de vida, de las mentalidades, de los nadies, de todo lo menospreciado por las historias oficiales, tendentes a centrarse en aspectos políticos excluyendo los sociales y marginales o periféricos.

Por supuesto el historiador no debe reducir su estudio al cine documental cuando se aproxima al mundo del séptimo arte, sino que debe analizar la ficción como parte de un legado que es documento de nuestro tiempo y memoria. En recientes declaraciones, el cineasta salmantino Basilio Martín Patino, famoso por sus documentales sobre el franquismo, defendía la relevancia en este sentido de las películas de ficción ${ }^{12}$.

No obstante, el término tiene en la actualidad cierta connotación peyorativa dentro del mundo del cine iberoamericano, pues como ya quedó constatado anteriormente, a la difusión del término dentro del mundo de las letras siguió una banalización del mismo. El mismo caso se ha dado en el cine, donde se ha calificado bajo la denominación de Realismo Mágico a casi cualquier película proveniente de América latina o que aborde una cierta temática. Ejemplo de todo esto son las declaraciones que hace en diciembre de 2001 el actor y director de cine mexicano Ignacio Ortiz a raíz del estreno de su película Cuento de hadas para dormir cocodrilos (2001) en el Festival de Cine Franco Mexicano de Acapulco; Ortiz cree que Realismo Mágico es un término que debe directamente desterrarse del séptimo arte ${ }^{13}$.

A la hora de analizar el cine relacionado con el Realismo Mágico debemos constatar desde un primer momento la destacada importancia de lo literario de ese cine. La inmensa mayoría de estas películas no son sino adaptaciones de obras literarias, cuentos o novelas. Sólo contadas excepciones confirman esta regla, como veremos a continuación.

11 VILlANUEVA, D. y VIÑA LISTE, J.M.: Trayectoria de la novela hispanoamericana actual. Del "Realismo Mágico" a los años ochenta. Madrid. Espasa Calpe, 1991.

12 El cineasta español Martín Patino considera que los filmes de ficción objetivan mejor la vida que las películas documentales pues, tras su aparente imparcialidad, éstas siempre tienen trampa y se convierten en un acto de propaganda. El director salmantino cree incluso que los filmes documentales deberían dejar de recibir ese nombre, pues sólo existen 'documentales personales' porque el montaje escamotea una parte de la realidad. El documental como tal es el NODO (el noticiero documental proyectado en los cines durante el franquismo), que da gato por liebre, aseguró el también productor realizador y guionista. Noticia aparecida en el portal Terra el día 7 de octubre de 2006.

13 Ortiz llega a declarar que su película no es realismo mágico. En todo caso sería una fantasía. Se ha malutilizado ese término y ahora a todo lo que no se le encuentra una explicación lógica, dramática, se le llama realismo mágico. En el cine se ha usado casi como folclor, como sinónimo de algo que no tiene rigor dramático o narrativo, y precisa que no está en contra de lo que se llamó realismo mágico dentro del boom de la literatura latinoamericana con obras como Pedro Páramo, de Juan Rulfo, y Cien años de soledad, del Nobel Gabriel García Márquez. Ignacio Ortiz ha dirigido películas como Hombre que no escucha boleros 1993, La orilla de la tierra 1994, Cuentos de hadas para dormir cocodrilos 2002. La Jornada, México D.F. 31 de diciembre de 2001. 
Las características de este cine coinciden casi en su totalidad con las enumeradas como características propias del Realismo Mágico, principalmente en la Literatura:

- Hay una presencia de elementos mágicos tal vez intuitivos, pero nunca explicados. Presencia asimismo relevante de lo sensorial como parte de la percepción de la realidad.

- El tiempo lo percibimos como cíclico, no como lineal, según tradiciones disociadas de la racionalidad moderna-occidental. Se distorsiona el tiempo, para que el presente se repita o se parezca al pasado, lo que puede confundir al espectador. En general, la relación entre el cine y el factor tiempo es muy singular. El director de cine ruso Andrei Tarkovsky hablaba del cine como el único arte que trabaja con el concepto de tiempo en sentido literal ${ }^{14}$. "Después de todo, ¿qué es una toma sino la fijación de una realidad?" llega a decir Tarkovsky.

- Transformación de las vivencias comunes y cotidianas en unas vivencias que incluyen experiencias "sobrenaturales" o "fantásticas".

- La temática del cine del Realismo Mágico también coincide con la de la literatura: la presencia de lo prehispánico o indígena (o elementos de origen africano) en la cosmovisión presentada, la diversidad de épocas históricas, lo destacado del mestizaje cultural, etc. En este punto hay que destacar la importancia de las protagonistas femeninas. La mujer actúa de puente entre lo real y lo irreal, entre los mundos que conviven de un modo más o menos armonioso dentro del Realismo Mágico, y también entre los tiempos pasados, presentes y futuros. Es además lo que une al ser humano con la naturaleza y todo lo que la forma; dentro de la sociedad de los hombre y dirigida por éstos, la figura de la mujer aparece dentro de estas películas con un protagonismo que la sitúa más allá de la simple espectadora pasiva que socialmente se le ha impuesto en toda cultura humana en general y en las culturas americanas en particular.

El cine del Realismo Mágico no es exclusivo de la cinematografía iberoamericana, como no los es su Literatura. Algunos autores anglosajones incluyen a realizadores que verdaderamente deberían incluirse dentro de lo fantástico, como es el caso de Tim Burton. Buenos ejemplos de cine del Realismo Mágico fuera de América Latina los podemos encontrar dentro de la cinematografía española. Dejando fuera de tal grupo a aquellas películas que no tienen nada que ver con él y sí con el surrealismo (como Un perro andaluz 1929 de L. Buñuel y S. Dalí), y dejando también a filmes que podríamos clasificarlas dentro de cierto surrealismo /humor absurdo (como Amanece que no es poco 1988, de José Luis Cuerda), encontramos tres largometrajes que podemos incluir dentro del Realismo Mágico cinematográfico en España: Vacas 1992, del realizador vasco Julio Médem; El bosque animado 1987 del manchego José Luis Cuerda; y Mararía 1998, del tinerfeño Antonio José Betancor.

Estas tres películas nos muestran por un dato muy significativo, la importancia de lo literario dentro del cine del Realismo Mágico: dos de las tres son adaptaciones al cine de novelas. Sólo Vacas presenta un guión original, obra del propio Médem y de Mikel Gaztambide. La película de Cuerda es una adaptación de la novela homónima de 1943 del gallego Wenceslao Fernández Flórez (llevada dos veces más a la gran pantalla: en 1945 por José Neches y en 2001 por Ángel de la Cruz y Manolo Gómez) y la película de Betancor se basa en la novela de 1973 del escritor canario Rafael Arozarena Doblado. Todas poseen rasgos característicos del Realismo Mágico, y en una de ellas es muy evidente la influencia latinoamericana sobre la novela y la posterior adaptación cinematográfica.

${ }^{14}$ TARKOVSKY, A: Esculpir en el tiempo. Madrid. Editorial Rialp, 1991. 
No es este el caso de El bosque animado, pues su autor la escribe en 1943, décadas antes del Boom editorial de los autores latinoamericanos. En el film de Cuerda (con guión de Azcona) aparecen los elementos definidores del Realismo Mágico, aunque no todos: la singular relevancia de los personajes femeninos del lugar; la aparición de un universo mágico, un bosque, que abarca todo lo apartado de la civilización, representada por el lejano mundo de la ciudad, y que representa dentro del microcosmos rural lo más recóndito de la condición humana; más allá de los tópicos rurales gallegos (supersticiones, brujerías, meigas) en el largometraje aparecen elementos como las ánimas errantes en pena (la Santa Compaña) que se aparecen a los habitantes-visitantes del bosque.

A pesar de la belleza del texto original, la película, oscilando entre lo trágico y lo cómico, no pasa de cierto retrato costumbrista de la Galicia rural, aunque los elementos citados nos acercan a un mundo y a unas mentalidades conectadas con el de otras zonas alejadas geográficamente pero relacionadas como veremos más adelante.

La película de Julio Médem Vacas narra una historia del mundo rural vasco a caballo entre los siglos XIX y XX. A lo largo de tres generaciones (el aizkolari, su hijo y su nieto) el espectador es testigo de los avatares de dos familias de un pequeño valle guipuzcoano, los Irigibel y los Mendiluce, familias que mantienen unas relaciones violentas, de rivalidades y odios que abarcan en el tiempo desde la última guerra carlista ( la acción comienza en 1875) hasta el comienzo de la Guerra Civil española en 1936.

La mezcla de lo trágico y lo mágico guarda cierta relación con el Realismo Mágico latinoamericano, aunque es el papel de las mujeres lo que puede representar un más claro paralelismo. El título del film revela como unos animales, las vacas, son receptoras de las obsesiones y miedos de los protagonistas humanos: los cuerpos de vacas muertas con las pezuñas amputadas, los ojos de las vacas mostrados como espejos distorsionantes de los protagonistas, su presencia en los bosques... pero lo mágico de la película de Médem va más allá de los seres vivos, y así el espectador es testigo de cómo un espantapájaros movido por el viento o el vuelo de un pedazo de madera que sale del tronco que corta el aizkolari casi cobran vida propia. De nuevo como en El bosque animado estamos ante una película que parece huir de los tópicos más oscuros del mundo rural vasco, un mundo habitado por leyendas y brujas reunidas en torno a akelarres míticos. Pero el director no puede ni quiere escapar de unos elementos mágicos que conviven perfectamente con el desarrollo de unos acontecimientos históricos (de la Historia más oficial, representado por las guerras) y con la historia propia del espacio endogámico y casi claustrofóbico del valle habitado por los protagonistas.

Por último, la Mararía de Betancor es una adaptación sui generis de la novela del fetasiano Arozarena. Narra la historia de María-Mararía, mujer lanzaroteña de belleza fatal deseada por todos los hombres de la isla y sólo poseída por los forasteros, temida y despreciada por las otras mujeres, acusada de brujería y que con su presencia hace callar a los perros y atraer a los cuervos, a quien aguarda un trágico final de autodestrucción. Tanto en la novela como en la película se encuentran influencias americanas ${ }^{15}$ : Betancor decide en el film incluir rituales de santería cubana, al parecer más vistosos que los de la brujería autóctona canaria ${ }^{16}$.

15 En la edición de 2003 de la editorial Septem de Santa Cruz de Tenerife, Manuel Torres Stinga escribe en una aproximación a la estructura narrativa de Mararía, que hay ciertos rasgos de la novela que la relacionan con el Realismo Mágico iberoamericano. Así, señala que en la novela se da una transmutación de la realidad local en su cosmos que trasciende la pura contingencialidad espacio-temporal, convirtiendo lo local en universal y permanente. No es de extrañar, por tanto, que más de un lector haya relacionado, mutatis mutandi, el Femés de Mararía con el Comala de Pedro Páramo. Más adelante apunta en relación con la indolencia los personajes de la isla que Arozarena, al igual que García Márquez con muchos moradores de Macondo, sitúa a sus personajes en la modorra de la siesta, bajo un sofocante calor e indiferentes al mundo circundante.

16 Sobre este tema destaca la obra de FAJARDO SPÍNOLA, Francisco: Hechicería y brujería en Canarias en la Edad Moderna, Gran Canaria, Cabildo Insular de Gran Canaria, 1992. 
Si con el Realismo Mágico iberoamericano lo local pasa a ser universal, la historia e intrahistoria de pequeñas comunidades pasa a cobrar relevancia más allá de sus fronteras espaciales y temporales, en Mararía asistimos al mismo proceso. La película basada en una novela de lectura obligatoria en casi todos los institutos de enseñanza secundaria en Canarias (la fama de la obra en las islas la convirtió en una especie de obra oficial) tuvo una gran aceptación al ser presentada en Japón, otro espacio insular a primera vista muy alejado por historia y mentalidad de una obra que venía del archipiélago que siglos antes fue confín del mundo conocido, el mundo mediterráneo. Tal aceptación se debió a que la historia de Mararía era similar al de Ryonen, la monja budista a la que se atribuyen algunos haikus que decidió quemarse la cara (según otras versiones, se la acuchilla) pues su enorme belleza había alterado hasta el extremo la vida sosegada del convento.

En estas tres películas españolas del Realismo Mágico de geografías tan aparentemente distantes entre sí como las representadas por Galicia, País Vasco y Canarias, encontramos unos elementos comunes (ambiente rural o insular lejano al mundo urbano e industrializado de las épocas en que se desarrollan las tramas, protagonismo de elementos mágicos, el papel especial jugado por las mujeres...) que se disponen junto a unas historias similares: los tres escenarios comparten rasgos parecidos. Uno de esos rasgos mágicos es el del protagonismo de los hechizos, brujas, meigas, etc que se corresponden con territorios tardíamente cristianizados donde la mezcla y la separación entre el cristianismo y lo pagano o precristiano tiene un peso destacado. Un proceso vivido hace siglos dentro del propio mundo mediterráneo, zona central de la civilización occidental. Otro sería el de los escenarios: un bosque, un valle pequeño, una isla desértica. Paisajes claustrofóbicos para el hombre de la ciudad, de la civilización, donde perduran mentalidades de otros tiempos o de un tiempo paralelo al del veloz ritmo de la vida moderna.

Para dar una breve ojeada al cine iberoamericano del Realismo Mágico podemos recordar de modo sucinto seis películas significativas, que reúnen tres elementos definitorios de este cine: su vinculación con la literatura, su relación con las culturas indias y el tratamiento que reciben los personajes femeninos, a menudo protagónicos. Estas películas son La nación clandestina, de Jorge Sanjinés; La vendedora de rosas, de Víctor Gaviria; Como agua para chocolate, de Alfonso Arau; El coronel no tiene quien le escriba, de Arturo Ripstein ; Pedro Páramo, de Carlos Velo, y La Tigra, de Camilo Luzuriaga.

La primera de ellas, La nación clandestina, es una película boliviana de 1989, dirigida por Jorge Sanjinés, realizador nacido en La Paz en 1936 autor de filmes como Ukamau 1966, Yawar Mallku 1969, El coraje del pueblo 1971, El enemigo principal 1973, Las banderas del amanecer 1982, Para recibir el canto de los pájaros 1995. En La nación clandestina Sanjinés realiza un trabajo de cámara en constante movimiento,en donde el relato lleva a la tesis de Sanjinés en torno al uso del 'plano secuencial integral' como recurso narrativo adecuado para la traducción visual de la concepción circular aymara, así como al indestructible vínculo del individuo de esa cultura con su entorno natural social. Casi la totalidad de la producción de este director boliviano gira en torno al mundo indígena de su país, especialmente del pueblo aymara.

La película nos cuenta la historia personal de Sebastián Mamani, un campesino renegado de su clase que vuelve a su pueblo a pagar sus culpas por prestar servicio como represor durante la dictadura, bailando la danza del Danzanti hasta morir, el, espera borrar su pasado, anhela un renacimiento. Sebastián representa lamentablemente, a una gran parte de la Bolivia que ha perdido su identidad cultural, gente que se avergüenza de su origen campesino, del color de su piel, de tener apellido aymara o quechua. El director combina en su largometraje el desarrollo del tiempo aymara con la evolución de unos acontecimientos históricos determinados del siglo XX boliviano: la Revolución de 1952, la reforma agraria, el papel de las comunidades aymaras, la represión estatal, la intervención estadounidense... No se puede considerar a esta película como 
plenamente integrada dentro del Realismo Mágico cinematográfico, pero el director combina sabiamente el cine de denuncia histórica y compromiso político con la intrahistoria boliviana de mediados de siglo XX, donde los pueblos indios estaban apartados del protagonismo político por minorías elitistas y mantenían una cosmovisión lejana al racionalismo materialista occidental cercano a planteamientos capitalistas-neoliberales.

Otra película iberoamericana que tampoco podríamos incluir totalmente dentro del Realismo Mágico pero que mantiene una serie de rasgos del mismo es la colombiana La vendedora de rosas, film de 1998 de Víctor Gaviria. El realizador nos narra la historia de unos niños que viven en las calles de Medellín, entre la droga y las músicas alegres y tristes del lugar. En palabras de Gaviria, Mónica, le vendedora de flores protagonista, es una adolescente que ha recibido todos los azotes de la intemperie, por debajo de su sombrero deshecho y su pelo mojado, debajo de su cabeza que da vueltas, permanece el criterio de la heroína. Es decir la vocecita digna y sin renunciar que morirá con ella.

En la película colombiana realidad y sueño quedan unidos por la droga. El mundo de las bandas, de la exclusión social y el desarraigo, rodean a la huérfana protagonista dentro de una obra que es casi un documental, pues aunque la historia narrada sea una ficción, los personajes son interpretados por niños que realmente vivían en las calles. La ficción es el rodeo que hacemos a través de la imaginación para llegar a la verdad de lo que está aquí mismo, a la verdad de la elusiva realidad nuestra de todos los días, escribió el director en 1998. La ausencia de la madre y la abuela hacen que la protagonista identifique a ésta última con la Virgen María; el director recurre a los sueños de la protagonista para revelarnos los anhelos más ocultos y sus sentimientos. La buena acogida del film en Cannes la convirtió en una de las películas iberoamericanas más conocidas por el gran público en los últimos años. Es el mismo caso que la mexicana Como agua para chocolate, de gran éxito por la fama de la novela homónima de 1989 de la escritora Laura Esquivel, que fue traducido a más de treinta idiomas.

La historia tiene tal aceptación que solo tres años después, en 1992, es llevada a la gran pantalla por el esposo de Esquivel, Alfonso Arau, quien a su vez la convierte en una gran producción de enorme éxito comercial dentro y fuera de México, llegando al gran público. Tan enorme que a partir de su comercialización surgieron no pocas películas en Estados Unidos y Europa donde las cocinas se convertían en escenarios de los deseos humanos y la gastronomía en un mapa sentimental con el que se identificaban públicos de diferentes latitudes.

De lo universal pasamos a lo concreto: Arau adapta bastante fielmente la novela, que cuenta una historia de amor y recetas únicas en el México fronterizo con los Estados Unidos de finales del XIX y principios del XX. Tita y Pedro ven obstaculizado su amor cuando Mamá Elena decide que Tita, su hija menor, debe quedarse soltera para cuidar de ella en su vejez. En medio de los olores y sabores de la cocina tradicional mexicana, Tita sufrirá largos años por un amor que perdurará más allá del tiempo. La película va más allá de ser una historia de novela romántica y en ella el espectador asiste a esa mezcla entre los universos del Realismo Mágico que ya se daban en la novela y el trasfondo político y social de la época histórica: la Revolución mexicana, el contacto entre lo anglosajón y lo hispano a través del fronterizo territorio del Río Grande... una historia que debía ser llevada al cine por contar visualmente algo que conecta con el gran público, y que tiene la suerte de alejarse tanto del cine comercial vulgar y barato como del cine de arte aburrido y pretencioso.

Otra curiosa adaptación al cine de una novela del Realismo Mágico es la de la obra de 1961 de Gabriel García Márquez El coronel no tiene quien le escriba, dirigida en 1999 por Arturo Ripstein. La coproducción hispano-mexicano-francesa es bastante más interesante para el conocimiento del Realismo Mágico en el cine que la adaptación de Crónica de una muerte anunciada, llevada al cine en Italia por Francesco Rosi en 1987. Cronaca di una 
morte annunciata es un largometraje pretencioso, poblado de famosos actores pero que no supera la calidad del film de Ripstein ${ }^{17}$.

Como en el famoso relato del cataquero el film cuenta la historia de un viejo coronel que no ha perdido la esperanza de que algún día llegue la carta en la que le anuncien la pensión que le prometieron. Todos en el pueblo saben que espera en vano, hasta su esposa, una esquelética mujer que padece el hambre y la pobreza mientras observa a su marido continuar todos los viernes con su solemne ritual para ir a recoger la carta que nunca llegará. Es posible encontrar aquí elementos de lo mágico: saltos en el tiempo, mezcolanza entre fenómenos fantásticos y situaciones reales... además la descripción del autor de la Colombia profunda de galleras, cine y pobreza la hacía merecedora de estar entre estas películas. García Márquez quedó encantado con el trabajo de Ripstein.

Y si destacada es la aportación de Gabo al Realismo Mágico literario, no menos lo es la del mexicano Juan Rulfo. Sobre Pedro Páramo, su obra llevada al cine por Carlos Velo en 1966, llegó a comentar García Márquez: Álvaro Mutis subió a grandes zancadas los siete pisos de mi casa con un paquete de libros, separó del montón el más pequeño y corto, y me dijo muerto de risa: ¡Lea esa vaina, carajo, para que aprenda! Era Pedro Páramo. Aquella noche no pude dormir mientras no terminé la segunda lectura. Nunca, desde la noche tremenda en que leí la Metamorfosis de Kafka en una lúgubre pensión de estudiantes de Bogotá -casi diez años atráshabía sufrido una conmoción semejante. Borges dejó escrito que Pedro Páramo es una de las mejores novelas de las literaturas de lengua hispánica, y aun de la literatura. Una obra así debía ser llevada a la gran pantalla, cosa que no tardó mucho en suceder: a la obra de 1955 sucede con pocos años de diferencia la película, de 1966. Esto se debía a la relevancia que tuvo en todo México, convirtiéndose en una suerte de novela nacional, aunque Rulfo sólo hablaba de su Jalisco natal. La película no logra la calidad del escrito original, pero mantiene elementos de lo mágico en la misma.

El espectador conocerá la historia de Juan Preciado hijo de Pedro Páramo y Dolores Preciado. Después de la muerte de su madre decide cumplirle la promesa de ir en busca de su progenitor y reclamar lo suyo. Juan Preciado desciende hasta Comala un pueblo lleno desolación, misterio y soledad tarde o temprano se encuentra en un pueblo lleno de incertidumbres que le hacen crear una imagen de un Pedro Páramo duro y severo; dueño y señor de muchas personas, animales y tierras. Todo en aquel lugar se comporta de una manera misteriosa y oscura, todas las voces que cree escuchar le hacen creer que todo lo que hay en el pueblo es amenazante e inquietante. Misteriosos ecos se encuentran en el pueblo; estos están tras el protagonista hasta el punto que escucha una fiesta que hay en el pueblo y este rumor aparece cada noche, pero contra todo esto Juan encuentra cierta irregularidad en las apariciones y rumores que ve y escucha. De unos y otros rumores que lo persiguen se da cuenta de cómo es en realidad el legendario Pedro Páramo, un cacique de Comala que tenía a su pueblo sometido y acostumbrado a su tiranía, a sus contradicciones y a sus decisiones arbitrarias.

Muchas mujeres fueron seducidas por Pedro Páramo entre ellas la madre de Juan Preciado; pero un testimonio de una mujer le hace comprender a Juan que llega tarde porque su padre esta muerto, entonces se encuentra con una sorpresa que le hace llenar de incertidumbre todo lo del pueblo, las personas que le dan su testimonio, y todo este pequeño universo es irreal e inerte, todo allí era muerte; ahí no se asusta ni se quiere ir. Este universo lo siente como suyo y al percibir esto también se da cuenta que él también está muerto.

17 Tampoco se incluye la adaptación cinematográfica de la novela de Isabel Allende La casa de los espíritus por ser una coproducción internacional dirigida por un danés, Bille August, en 1993. 
Tanto en la obra literaria como en la película encontramos casi todos los elementos del Realismo Mágico en Pedro Páramo. El tratamiento del tiempo, el trasfondo de los acontecimientos históricos (como la Revolución mexicana tratada sin épica) conviviendo con una temática tan típicamente mexicana (pero sin ser tratada desde el tópico) como es la relación con la muerte y con los muertos, y el destacado papel de los personajes femeninos. La siguiente y última película está protagonizada por una mujer; si comenzamos con un film de evidente temática indígena, acabaremos con otro donde la protagonista es conocida por su poder que la relaciona con el animal totémico por excelencia para las culturas indígenas americanas.

La película ecuatoriana La Tigra, dirigida en 1990 por el lojano Camilo Luzuriaga, está basada en un relato del escritor José de la Cuadra, quien en la segunda edición de su libro Horno, de 1940, incluyó el cuento homónimo ambientado en el interior de las provincias costeras del Ecuador de los años treinta, una zona periférica y marginada en la que el olvido de las autoridades y de sus leyes hace creíble el ambiente que se describe. Un ambiente donde fantasía y realidad se combinan con una naturaleza salvaje que sirve de escenario para una historia de mujeres. Algunos consideran a este texto un precedente del Realismo Mágico; en mi opinión puede perfectamente integrarse dentro del mismo al igual que la película.

Para Helga Stephenson La Tigra es una fuerte, hermosamente evocativa película que capta las contradicciones de las opuestas fuerzas de la naturaleza versus civilización, y feminidad versus control machista ${ }^{18}$. La película nos cuenta que La Tigra no es otra que Francisca, la mayor de tres hermanas huérfanas que regentan una pequeña hacienda y fonda de viajeros en el corazón del Ecuador costero y rural.

La predicción del curandero Masablanca les advertía a las hermanas mayores, Francisca La Tigra y Juliana, que para conservar sus tierras y su sustento además de para redimir sus pecados, deben velar por la permanente virginidad de la hermana menor, Sara. Mientras esto ocurre ambas hermanas mayores disfrutan de todos los placeres sensuales: bailes, alcohol, amantes... Pero la aparición de Don Clemente, un vendedor ambulante que desea casarse con Sara precipita los acontecimientos y hará que estalle la tensión entre hermanas. El enfrentamiento es tal que provoca la intervención de las autoridades llamadas por el vendedor, que acusa a Francisca de secuestrar a su hermana menor.

Lo más relevante del largometraje desde el punto de vista del Realismo Mágico es que el mote de Francisca no alude sólo al enorme poder que la protagonista poseía sobre los habitantes del microcosmos que nos revela Luzuriaga. La Tigra posee una especial conexión con el jaguar, el animal mítico por excelencia de todas las cosmovisiones indias de las Américas. Francisca se adueña del alma del animal, y de acuerdo con una tradición extendida que dota a mujeres poderosas y sensuales de la capacidad de transformarse en felinos por la noche, se vuelve tigra (jaguar) para recorrer el monte en libertad huyendo del mundo de los hombres. Para las cosmovisiones de muchas culturas prehispánicas el tigre o jaguar representaba el espíritu más poderoso de toda la creación, un ser que iba más allá de lo que en nuestra civilización occidental judeocristiana representa el león. Ya fuera en las culturas amazónicas, en las andinas preincaicas o en el mundo mesoamericano, donde en jade se tallaban figuras de chamanes arrodillados con rostro y manos transformándose en jaguar, figura equivalente en cierto modo a la Dafne de Bernini, el jaguar representaba toda la fuerza de la naturaleza, el ser que canaliza las energías del universo, y que en el caso de la literatura y el cine del Realismo Mágico, queda representado por la figura de la mujer.

18 PÉREZ MURILLO, María Dolores y FERNÁNDEZ, David (coord..): Asociación Intrahistoria y Oralidad. La memoria filmada. América latina a través de su cine. Madrid, Ed. IEPALA., 2002. 
Este largometraje ecuatoriano es quizá el que mejor resuma de modo gráfico la especial relación existente entre el cine iberoamericano, la literatura y la Intrahistoria de América Latina a través del Realismo Mágico. No parece casual que sea la figura de la mujer la que haga una labor de puente entre estos diversos ámbitos. Una figura femenina es la que enlaza la Historia (entendida como lo oficial, el relato establecido y dirigido políticamente) con la Intrahistoria, entendida como la Historia al margen de lo establecido, la vida o vidas que como definía Unamuno nunca serían un titular de ningún periódico.

En la actual sociedad de la información, con unos medios de comunicación poderosísimos bajo el control de fuertes poderes fácticos, el historiador encuentra en un determinado cine una gran herramienta de difusión de la Historia y sobre todo, de la Intrahistoria. Intrahistoria que viene a enriquecer unos conocimientos necesitados de reflexión y amplitud de miras y puntos de vista. Labor ésta que realiza la Literatura iberoamericana - y dentro de ella, un Realismo Mágico como término convertido en intrahistoria de la misma, después de su excesiva utilización. En este caso, se difunde la Literatura y la Intrahistoria a través de un cine convertido en excepcional instrumento de investigación y didáctico, en fuente y objeto de análisis. 